\title{
PREDICTING CAPACITIES OF RUNWAYS SERVING NEW LARGE AIRCRAFT
}

\author{
Kasthurirangan Gopalakrishnan
}

\author{
Research Scientist, 353 Town Engineering Building, Dept of Civil Engineering, Iowa State University, Ames, \\ IA 50011, USA.E-mail: rangan@iastate.edu
}

Received 28 June 2007; accepted 20 November 2007

\begin{abstract}
This paper presents a simplified approach for predicting the allowable load repetitions of New Large Aircraft (NLA) loading for airfield runways based on Non-Destructive Test (NDT) data. Full-scale traffic test results from the Federal Aviation Administration's National Airport Pavement Test Facility (NAPTF) were used to develop the NDTbased evaluation methodology. Four flexible test pavement sections with variable (unbound layer) thicknesses were trafficked using six-wheel and four-wheel NLA test gears until the test pavements were deemed failed. Non-destructive tests using a Heavy Weight Deflectometer (HWD) were conducted prior to the initiation of traffic testing to measure the pavement surface deflections. In the past, pavement surface deflections have been successfully used as an indicator of airport pavement life. In this study, the HWD surface deflections and the derived Deflection Basin Parameters (DBPs) were related to functional performance of NAPTF flexible pavements through simple regression analysis. The results demonstrated the usefulness of NDT data for predicting the performance of airport flexible pavements serving the next generation of aircrafts.
\end{abstract}

Keywords: new generation aircraft, National Airport Pavement Test Facility (NAPTF), heavy weight deflectometer (HWD), surface deflection, airport flexible pavement, rutting.

\section{Introduction}

The impact of New Large Aircraft (NLA), such as the Boeing 777 aircraft, on existing and new airport pavements is an important issue facing the aviation industry today. Following Russia's Antonov AN 225, the world's largest aircraft, McDonell Douglas, Boeing and Airbus Industrie are all developing NLA comparable in size to the Antonov. The increased wheel loads, higher tire pressures and complex landing gear configurations of the NLA have generated widespread concern about their impact on airport pavement life and performance and about their suitability for use in airports. Recognizing this issue, the U.S. Federal Aviation Administration's (FAA's) National Airport Pavement Test Facility (NAPTF) was constructed to generate full-scale test data needed to verify/develop advanced airport pavement thickness design procedures. The NAPTF is located near Atlantic City International Airport, New Jersey.

In a recent series of traffic tests conducted at NAP$\mathrm{TF}$, four flexible pavement sections with variable granular subbase thicknesses (referred to as Construction Cycle 3 or CC3) were subjected to repeated loading of six-wheel and four-wheel New Large Aircraft (NLA) landing gears until the pavement sections were deemed failed. The
CC3 traffic testing was started on September 3, 2002 and was completed by October 18, 2002.

The four flexible pavement sections (LFC1, LFC2, LFC3, and LFC4) were constructed over a low-strength subgrade (target California Bearing Ratio [CBR] of 3) which already existed from a previous construction cycle (Construction Cycle 1 or CC1). The label "LFC" refers to a conventional granular-base pavement built over a low-strength subgrade. By Hayhoe (2004), the design lives of the CC3 pavement test items varied from 200 to 36,000 passes based on structural analysis using the FAA's layered elastic airport pavement design program, LEDFAA. The LFC1 test section was $12.2-\mathrm{m}$ ( $40-\mathrm{ft}$ ) long and LFC4 was $24.4-\mathrm{m}(80-\mathrm{ft})$ long while both LFC2 and LFC3 spanned $18.3 \mathrm{~m}$ (60 ft) each.

Cross-sectional views of as-constructed CC3 flexible test sections are shown in Fig. 1. The items P-209 base (crushed rock), P-154 subbase (gray quarry blend fines) and P-401 Asphalt Concrete (AC) used in the construction of test items are as per standard specifications detailed in the FAA Circular No. AC 150/5370-10A. A MH-CH soil classification (ASTM Unified Soil Classification System) material known as County Sand and Stone Clay (CSSC) was used for the low-strength subgrade. The naturally-occurring sandy-soil material (SW-SM soil classification) at 
the NAPTF site underlies each subgrade layer. The NAPTF materials characterization test results are stored in a database which is available for download or direct access on the FAA Airport Pavement Technology Website. Research, presented by Hayhoe, Garg (2001).

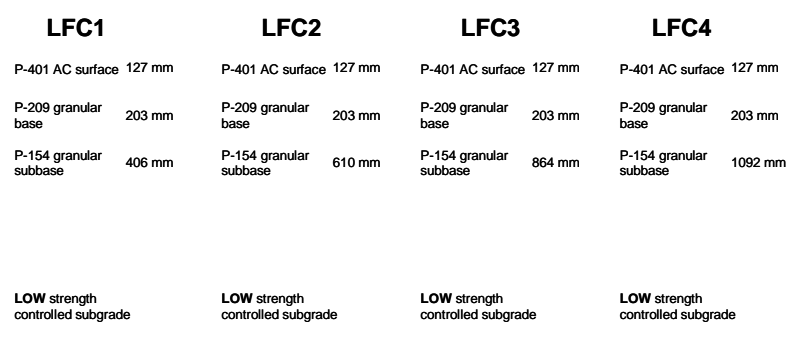

Fig. 1. Cross-sections of as-constructed NAPTF flexible test sections

Non-destructive tests (NDTs) using a Heavy Weight Deflectometer (HWD) were conducted prior to traffic testing to evaluate the uniformity of the test sections. During traffic testing, Transverse Surface Profile (TSP) measurements as well as straightedge rut depth measurements were made at frequent intervals to monitor the progression of pavement rutting. In the past, pavement surface deflections have been successfully used as an indicator of airport pavement life. This paper describes the development of a HWD-based evaluation procedure to predict the allowable NLA gear passes for airport flexible pavements. Although, the results are applicable specifically for the six-wheel and four-wheel NLA gears used at NAPTF, the methodology can be easily extended to prototype NLA gear loading with additional data from such full-scale traffic tests. The pavement rutting performance (capacity) was defined in terms of number of load repetitions to reach specific rut depth levels based on wellknown pavement distress criteria.

\section{Non-destructive tests}

By Chan et al. (1993), Holt et al. (2002) and Gopalakrishnan and Thomson (2005), the HWD is a heavier loading Falling Weight Deflectometer (FWD), and is commonly used to test the structural integrity of airport pavements non-destructively. The HWD measures pavement surface response (i.e., deflections) from an applied dynamic load that simulates a moving wheel of an aircraft at moderate speeds. Studies by Bush and Baladi (1989) and Tayabji, Lukanen (2000) have addressed the interpretation of pavement surface deflection measurements using FWD/HWD as a tool to characterize pavementsubgrade systems. The deflection data that are collected with the HWD equipment can provide both qualitative and quantitative data about the strength of a pavement at the time of testing, see FAA Advisory Circular (2004).

At the NAPTF, HWD tests were conducted on August 27, 2002 to evaluate the uniformity of the CC3 flexible test sections. The HWD tests were conducted using a KUAB $2 \mathrm{~m}$ HWD device acquired by the FAA. The FAA HWD equipment operates on the principle of dropping weights on a series of hard, rubber buffers separated by a second series of weights and buffers which are connected to a loading plate resting on the pavement surface. These two mass systems results in a consistent and uniform, half-wave sine curve for the loading pulse. The loading plate is segmented into quarters to ensure that the loading force is evenly distributed. Weights and buffers can be added, or removed as necessary, to adjust peak load and loading time. The loading pulse shape is also influenced by the combination of weights and buffers utilized. By Guo, Marsey (2001), the drop heights can be adjusted to control the peak load.

The FAA HWD equipment was configured with a 305mm (12-in.) loading plate and a 27-30 msec pulse width was used during testing, this presented by Guo, Marsey (2001) and McQueen et al. (2001). HWD tests were performed at nominal force amplitudes of $53-\mathrm{kN}(12,000-\mathrm{lb}), 106-\mathrm{kN}$ (24,000-lb), and $160-\mathrm{kN}(36,000-\mathrm{lb})$. This study focused on the $160-\mathrm{kN}(36,000-\mathrm{lb}) \mathrm{HWD}$ test results.

During HWD testing, the AC pavement temperature was $25.5^{\circ} \mathrm{C}\left(78{ }^{\circ} \mathrm{F}\right)$. The HWD test locations in each pavement test section are illustrated in Fig. 2. During traffic testing, the six-wheel traffic gear was centered on LANE 2 (north side) and the four-wheel traffic gear on LANE 5 (south side). The surface deflections were measured with seven geophones spaced at $30.5-\mathrm{cm}(12-$ in.) intervals $\left(D_{0}\right.$ to $\left.D_{6}\right)$ starting with the load center: $0 \mathrm{~mm}\left(D_{0}\right), 305 \mathrm{~mm}\left(D_{1}\right), 610 \mathrm{~mm}\left(D_{2}\right), 914 \mathrm{~mm}\left(D_{3}\right)$, $1219 \mathrm{~mm}\left(D_{4}\right), 1524 \mathrm{~mm}\left(D_{5}\right)$, and $1830 \mathrm{~mm}\left(D_{6}\right)$. The HWD test sequences were repeated at 3-m (10-ft) intervals along the test lanes as shown in Fig. 2.

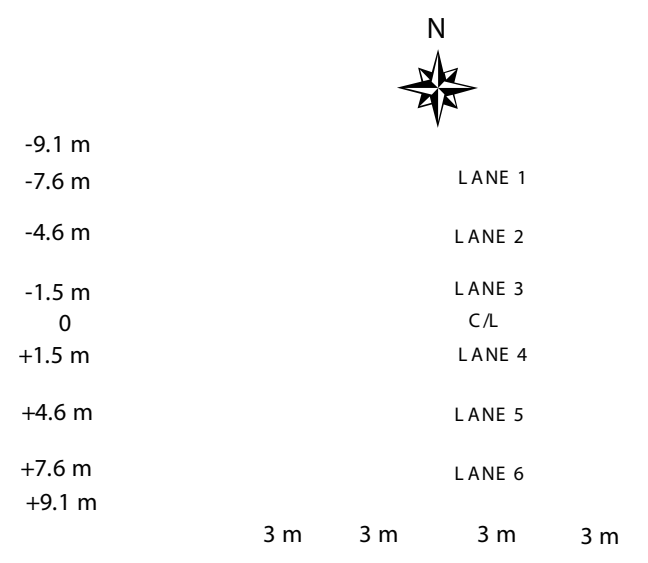

Fig. 2. Schematic diagram of Heavy Weight Deflectometer (HWD) test locations

\section{Analysis of non-destructive test data}

A distinctive feature of the CC3 flexible test sections is that the P-154 granular subbase thickness is the only structural variable and thus, the exclusive effect of granular subbase thickness on response and performance of these test sections can be studied. The representative pavement surface deflection basins obtained with $160-\mathrm{kN}(36,000-\mathrm{lb})$ HWD loading are compared in figure 3 for all four test sections. The maximum surface deflection $D_{0}$ is generally a function of the loading plate, applied load, and the pavement structure as a whole 
whereas the deflections at farther offsets from the load center $\left(D_{3}\right.$ and greater) are predominantly governed by the subgrade properties.

The influence of subbase thickness is clearly reflected in the maximum surface deflections $\left(D_{0}\right)$ (see Fig. 3). As the subbase thickness increased from $610 \mathrm{~mm}$ (24 in.) in LFC2 to $864 \mathrm{~mm}$ (34 in.) in LFC3 (difference of $254 \mathrm{~mm}$ ), the $D_{0}$ decreased from $2.7 \mathrm{~mm}$ (105 milli-inches or mils) to $2.0 \mathrm{~mm}$ ( $80 \mathrm{mils}$ ) (difference of $0.7 \mathrm{~mm}$ ). Whereas, for an increase of $228 \mathrm{~mm}$ (9 in.) in subbase thickness from LFC3 to LFC4, the corresponding difference in deflection was only $0.24 \mathrm{~mm}$ (9 mils).

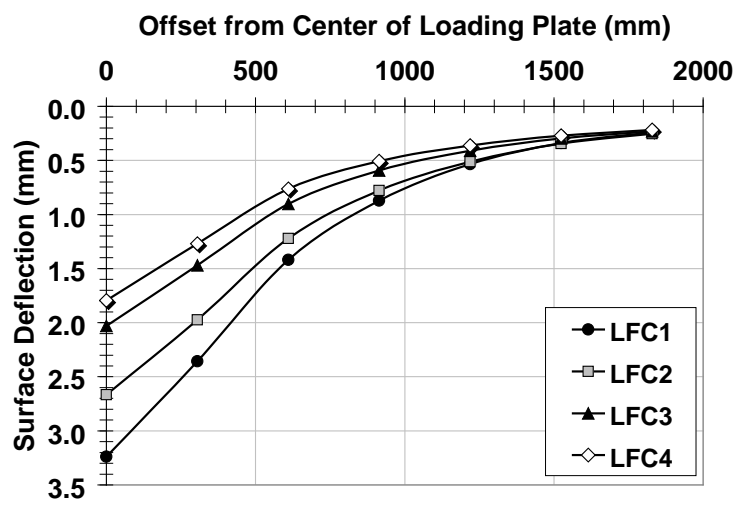

Fig. 3. HWD surface deflection basins at a sample test location at zero-traffic repetitions

In this study, apart from the surface deflections, certain Deflection Basin Parameters (DBPs) were also considered. Deflection basin parameters (DBPs), by Hossain, Zaniewski (1991), are widely used for three major applications: (a) to check the structural integrity of in-service pavements, (b) to relate to critical pavement responses, and (c) to calculate the in situ layer moduli of the pavements. Based on a comprehensive literature review, the most widely used and effective DBPs were identified: AREA, Area Under Pavement Profile (AUPP), Impact Stiffness Modulus (ISM), Surface Curvature Index (SCI), Base Curvature Index (BCI), and Base Damage Index (BDI).

The AREA shape parameter defines the stiffness of the pavement structure as a shape factor, investigated by Hoffman, Thompson (1982). It is the partial area under the deflection basin curve (normalized with respect to $D_{0}$ ). The AUPP is also a deflection basin shape parameter and its definition is complimentary to the AREA parameter, i.e., lower AUPP corresponds to higher pavement stiffness and vice versa by Hill, Thompson (1989). The ISM is computed as the ratio of FWD/HWD plate load over maximum surface deflection $\left(D_{0}\right)$ and is frequently used in airport pavement evaluation by Bush, Thompson (1990).

The SCI can provide information on changes in relative strength of the near-surface layers, especially the $\mathrm{AC}$ layer. Based on their finite element analyses, $\mathrm{Xu}$ et al. (2001) found that for a certain thickness of the AC layer, the AC moduli and SCI values exhibit an approximately linear relationship in a log-log scale. The BCI is a subgrade condition indicator especially in aggregate base pavements and is strongly related to the subgrade modulus by Horak (1987) and Kilareski, Anani (1982). The BDI is related to base layer modulus and is a critical DBP for subgrade condition evaluation in full-depth pavements. Based on HWD deflection basins collected at frequent intervals during NAPTF trafficking on the CC1 flexible pavement test sections, Gopalakrishnan, Thompson (2005) concluded that these DBPs are effective in characterizing the structural degradation in flexible airport pavements.

A summary of DBPs used in this study and their definitions are summarized in Table 1. In Fig. 4, the DBP values obtained for each test section are compared. The differences in magnitudes between LANE 2 (6-wheel traffic lane) and LANE 5 (4-wheel traffic lane) values are not significant. The ISM and AREA values calculated along the length of the CC3 test pavement are displayed in Fig. 5.

Table 1. Deflection basin parameters considered in this study

\begin{tabular}{|c|c|}
\hline DBP & Formula \\
\hline AREA & $\frac{6\left(D_{0}+2 D_{1}+2 D_{2}+D_{3}\right)}{D_{0}}$ \\
\hline AUPP & $\frac{5 D_{0}-2 D_{1}-2 D_{2}-D_{3}}{2}$ \\
\hline ISM & $\frac{P}{D_{0}}$ \\
\hline SCI & $D_{0}-D_{1}$ \\
\hline BCI & $D_{2}-D_{3}$ \\
\hline BDI & $D_{1}-D_{2}$ \\
\hline
\end{tabular}

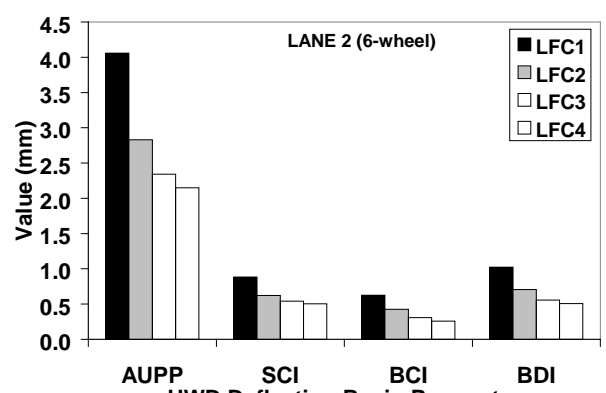

a

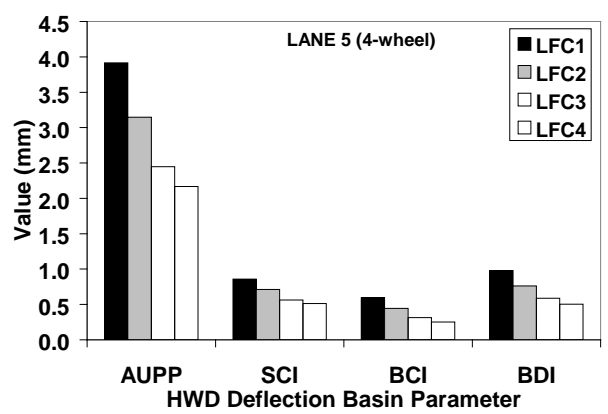

Fig. 4. Comparison of deflection basin parameters: $\mathrm{a}$ - LANE 2; b - LANE 5 


\section{NAPTF traffic testing}

The CC3 test sections were trafficked using a test vehicle with a six-wheel (dual-tridem) aircraft gear (resembling Boeing 777 landing gear) on the north side traffic path (LANE 2 in Fig. 2) and a four-wheel (dual-tandem) aircraft gear on the south side (LANE 5 in Fig. 2). The gear configuration details for the test gears are shown in Fig. 6 . The wheel load was set to 25 tonnes (55,000-lbs) and the tire inflation pressure was $1,688 \mathrm{kPa}(245 \mathrm{psi})$. The traffic speed was set to $8 \mathrm{~km} / \mathrm{h}(5 \mathrm{mph})$. The traffic tests were conducted during September and October of 2002, immediately after construction of the test sections.

To realistically simulate transverse aircraft movements, a wander pattern consisting of a fixed sequence of 66 vehicle passes ( 33 traveling in the east direction and 33 traveling in the west direction), arranged in nine equally spaced wander positions (or tracks) at intervals of $260 \mathrm{~mm}$
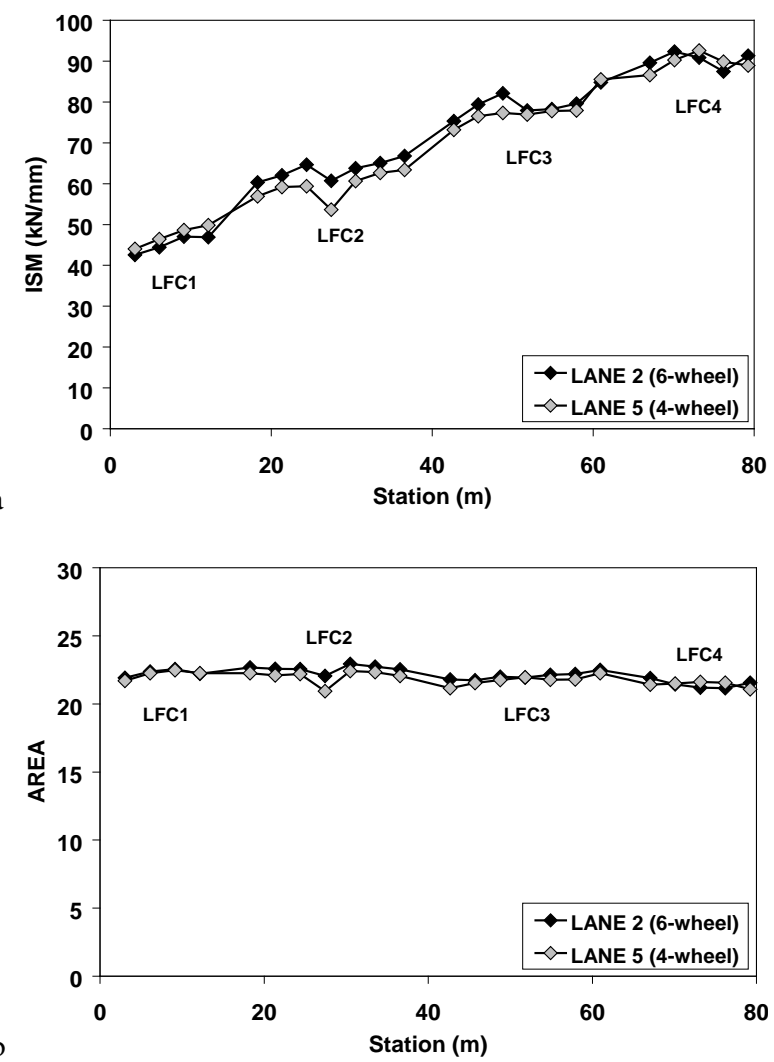

Fig. 5. Variability in deflection basin parameters along test pavement: a - Impact Stiffness Modulus (ISM); b - AREA

$\begin{array}{ll}\begin{array}{c}\text { 6-wheel Gear } \\ 1372 \mathrm{~mm}\end{array} & \begin{array}{c}\text { 4-wheel G ear } \\ 1372 \mathrm{~mm}\end{array} \\ & \\ 1448 & 1448 \\ \mathrm{~mm} & \mathrm{~mm} \\ 1448 & \\ \mathrm{~mm} & \end{array}$

Fig. 6. Traffic test gear configuration details
(10.25 in.), was used during the traffic testing. This wander pattern simulates a normal distribution of aircraft traffic with a standard deviation $(\sigma)$ of $775 \mathrm{~mm}$ (30.5 in) that is typical of multiple gear passes in airport taxiways.

According to the FAA, the primary objective of the NAPTF trafficking tests was to determine the number of load applications to cause shear failure in the subgrade. Per NAPTF failure criterion, adopted from the U.S. Army Corps of Engineers multiple-wheel heavy gear load tests conducted at Vicksburg, Mississippi, this is reflected as 25.4-mm (1-in.) surface upheaval adjacent to the traffic lane, see investigation by Ahlvin et al. (1971).

It is important to note that in the 25.4-mm (1-in.) surface upheaval failure criterion, there is no limit on the maximum rut depth. Thus, a surface upheaval of 25.4-mm (1-in.) may be accompanied by a $13-\mathrm{mm}(0.5-$ in.) rut depth or rut depths in excess of 50 to $75 \mathrm{~mm}$ (2 to 3 in.) with no limit on the maximum allowable rut depth. However, according to the Unified Facilities Criteria (UFC), rut depths in excess of $25.4 \mathrm{~mm}$ (1 in.) is considered as "High" severity rutting and it constitutes a significant functional failure requiring major maintenance activities. This presented in US COE (2001).

\section{Pavement performance}

To monitor the progression of rutting in NAPTF test sections, Transverse Surface Profile (TSP) measurements as well as rut depth measurements using a $3.66 \mathrm{~m}$ - (12 ftlong straightedge were made throughout the traffic testing. The rutting results based on TSP measurements are discussed in this paper. A non-contact laser profiling device with a span of $6.5 \mathrm{~m}(21.5 \mathrm{ft})$ and a range of $20.3 \mathrm{~cm}$ (8 in.) was used to measure profiles at three locations (east, west, and center) within each test item.

As mentioned previously, the CC 3 traffic tests began on September 3, 2002 and ended on October 18, 2002. Pavement temperatures in the AC layer were monitored using Omega Thermistor temperature gages throughout the traffic testing. The variation in P-401 AC layer mid-depth temperature during traffic testing is shown in Fig. 7. It was found that the AC temperatures did not vary with test sections (as NAPTF is an indoor test facility) and therefore the average values obtained from all four test sections are plotted.

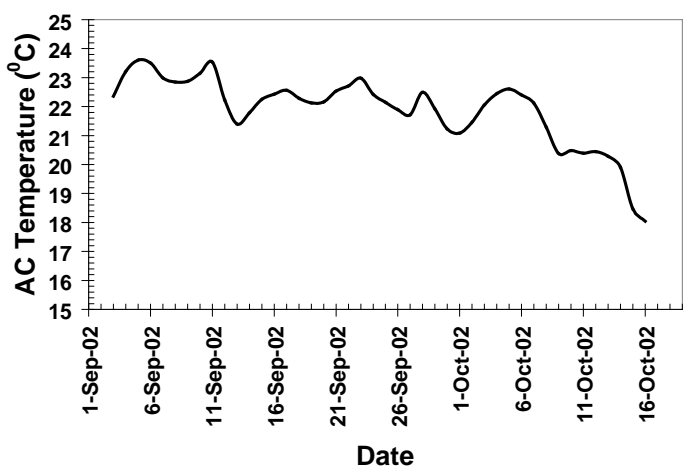

Fig. 7. Variations in asphalt concrete (AC) pavement temperature during NAPTF traffic testing 
The LFC1 section showed rapid accumulation of rutting and failed at 90 passes on the 6-wheel traffic path and at 132 passes on the 4 -wheel traffic path as per NAPTF failure criterion. In LFC2, the 6-wheel traffic lane reached failure at 1,100 passes, while the 4 -wheel traffic lane failed at around 3,000 passes. In both LFC3 and LFC4, the traffic wheel load magnitude was increased from 25 tonnes (55 kip) to 29.5 tonnes (65 kip) after 4000 passes to accelerate failure. The 6-wheel traffic lane of LFC3 failed at 21,000 passes and trafficking was terminated on LFC4 at 23,000 passes.

The magnitudes of rut depths at failure in LFC1 and LFC2 sections were approximately $102 \mathrm{~mm}$ (4 in.) and $203 \mathrm{~mm}$ (8 in.), respectively. At the termination of traffic testing, the rut depths in the LFC3 and LFC4 sections were approximately $203 \mathrm{~mm}(8 \mathrm{in}$.) and $152 \mathrm{~mm}(6 \mathrm{in}$.), respectively by Gopalakrishnan (2004). The development of surface rutting in the NAPTF test sections under repeated traffic loading is displayed in Fig. 8. Note that the traffic wheel load magnitude was increased from 25 tonnes (55 kip) to 29.5 tonnes (65 kip) in LFC3 and LFC4 sections at 4000 passes as shown in the Fig. Using the maxim surface rut depths obtained from the TSPs, rutting analyses were performed by applying the Power model, presented by Monismith et al. (1975) and the pavement surface rutting rate model, presented by Gopalakrishnan (2004). The results of rutting analyses by Gopalakrishnan, Thompson (2006) are discussed in detail elsewhere.

After the completion of traffic testing, trench studies were conducted on LFC1 and LFC2 sections. Trench studies revealed that in both the sections, rutting occurred pre-dominantly in P-209 base and P-154 subbase layers. Trench studies were not conducted on LFC3 and

a
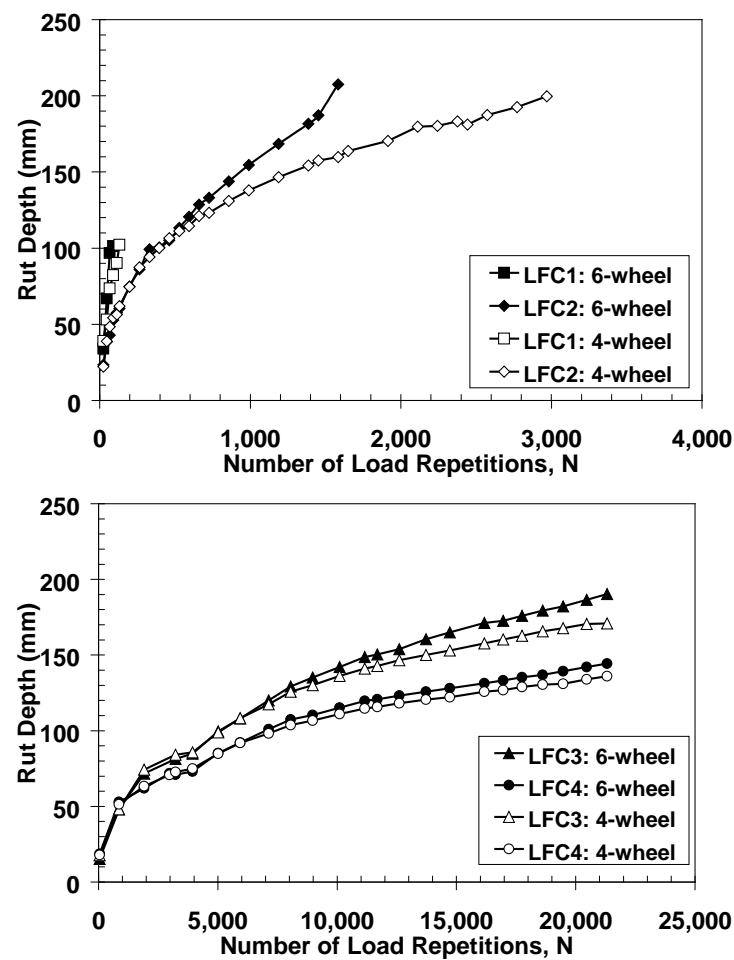

Fig. 8. Development of surface rutting with trafficking
LFC4 test sections. The CBR values, computed as the average of the measurements from acceptance surface, trench surface, and trench pits at $30.5 \mathrm{~cm}$ (12 in.) and $61 \mathrm{~cm}(24 \mathrm{in}$.) from the surface of the subgrade, were approximately 4.0 for both LFC1 and LFC2, see investigation by Hayhoe (2004).

\section{Estimate of performance using non-destructive test data}

According to the NAPTF failure criterion, failure is defined as the presence of at least 25.4-mm (1-in.) surface upheaval adjacent to the traffic lane. This is considered to reflect structural failure in the subgrade. However, as noted earlier, this failure criterion is not consistent with respect to rut depths. The CC1 trafficking results, by Gopalakrishnan (2004), showed that the NAPTF failure criterion did not yield consistent rut depths. The rut depths varied between 50.8 to $127 \mathrm{~mm}$ ( 2 to $5 \mathrm{in}$.) during CC1 traffic tests.

Ultimately, the surface rut depths will dictate the performance of the pavement and not the surface upheaval. In this study, the performance measure was defined in terms of number of wheel load repetitions to reach rut depth levels of $12.7 \mathrm{~mm}$ (0.5 in.), $25.4 \mathrm{~mm}$ (1 in.), $38.1 \mathrm{~mm}$ (1.5 in.), etc. Performance criteria of this type based on functional failure will limit the total surface rutting and ensure stable rutting performance. This approach, by Gopalakrishnan, Thompson (2007), was successfully used in developing response-performance relations based on $\mathrm{CC} 1$ trafficking data.

In CC3 test sections, rutting accumulated rapidly under trafficking and the rut depths exceeded 25.4-mm (1-in.) in fewer than 50 passes in the LFC1 and LFC2 sections. Therefore, it is not feasible to consider $25.4-\mathrm{mm}$ (1-in.) rut depth level or lower in relating structural responses to rutting performance based on functional failure criteria. In this study, 38.1-mm (1.5-in.) and 50.8-mm (2-in.) rut depth levels were considered.

Surface deflection has been shown to be a reliable pavement structural response indicator for predicting general performance, see NCHRP Project (1990). The pavement surface deflections are easily measurable (using a non-destructive test device such as HWD) compared to other responses, such as stresses and strains, and are the basic response of the pavement structure to the applied load, see Garg, Marsey (2002) investigation. Many highway agencies such as California Department of Transportation (DOT), the Asphalt Institute, Minnesota DOT, the Transport Road Research Laboratory (TRRL) utilize surface deflection for designing AC overlays, predicting future performance, and considering wheel loading magnitude effects, see NCHRP Project (1990).

In a study by Ahlvin (1991) conducted at Waterways Experiment Station (WES), a strong relation was found between elastic (or recoverable) deflection and allowable load repetitions on flexible pavements. Bush, Thompson (1990) developed a FWD-based evaluation procedure to predict the allowable F-4 aircraft load and the allowable aircraft passes for marginal flexible pavements. Analysis of NAPTF 
CC1 trafficking data showed that the rutting performance of flexible test sections (defined in terms of number of load repetitions to reach specific rut depth levels) is related to initial HWD surface deflection basin parameters.

In this study, regression analyses were conducted to predict the number of load repetitions to functional failure $\left(\mathrm{N}_{\mathrm{RD}}\right)$ as a function of initial $160-\mathrm{kN}(36,000-$ lb) HWD responses. The results of regression analyses are summarized in Tables 2 and 3, for rut depth levels of $38.1-\mathrm{mm}$ (1.5-in.) and 50.8- $\mathrm{mm}$ (2-in.) respectively. A total of 8 cases (4 test sections $\times 2$ test gears/HWD test lanes) were considered in establishing the regression models. Note that the average AC temperature at the time of CC3 HWD testing was $25.5^{\circ} \mathrm{C}\left(78^{\circ} \mathrm{F}\right)$. The surface deflections and DBPs could not be corrected to a standard reference temperature of $21.1^{\circ} \mathrm{C}\left(70{ }^{\circ} \mathrm{F}\right)$ as there were not sufficient data to establish temperature correction equations.

Among the DBPs, $D_{3}$, ISM, BCI and $D_{0}$ showed stronger correlations with the number of load repetitions to reach functional failure. Among these, $D_{3}$ showed the strongest correlation. Note that $D_{3}$, surface deflection measured at an offset of $914 \mathrm{~mm}$ (36 in.) from the center of HWD plate, is considered to reflect the subgrade properties. All the $R^{2}$ values were statistically significant at the $99 \%$ probability level. These results indicate the

Table 2. Summary of regression prediction models for number of load repetitions to 38.1-mm (1.5-in) rut depth

\begin{tabular}{|c|c|c|c|c|}
\hline \multicolumn{5}{|c|}{ Regression model: $\log \left(N_{1.5}\right)=A+b X$} \\
\hline$A$ & $X$ & $b$ & $R^{2}$ & $\begin{array}{c}\text { Standard Error } \\
\text { of Estimate } \\
\text { (SEE) }\end{array}$ \\
\hline 5.230 & $D_{0}(\mathrm{~mm})$ & -1.181 & 0.961 & 0.153 \\
\hline 5.190 & $\begin{array}{c}\text { AUPP } \\
(\mathrm{mm})\end{array}$ & -0.988 & 0.913 & 0.229 \\
\hline-0.624 & $\begin{array}{c}\text { ISM (kN/ } \\
\mathrm{mm})\end{array}$ & 0.0430 & 0.984 & 0.098 \\
\hline 5.605 & $D_{3}(\mathrm{~mm})$ & -4.675 & 0.997 & 0.042 \\
\hline 5.340 & $\mathrm{SCI}(\mathrm{mm})$ & -4.570 & 0.878 & 0.272 \\
\hline 4.625 & $\mathrm{BCI}(\mathrm{mm})$ & -5.772 & 0.973 & 0.129 \\
\hline 5.063 & $\mathrm{BDI}(\mathrm{mm})$ & -3.905 & 0.938 & 0.193 \\
\hline
\end{tabular}

Table 3. Summary of regression prediction models for number of load repetitions to 38.1-mm (1.5-in) rut depth

\begin{tabular}{|c|c|c|c|c|}
\hline \multicolumn{5}{|c|}{ Regression model: $\log \left(N_{1.5}\right)=A+b X$} \\
\hline$A$ & $X$ & $b$ & $R^{2}$ & $\begin{array}{c}\text { Standard Error } \\
\text { of Estimate } \\
(\mathrm{SEE})\end{array}$ \\
\hline 6.016 & $D_{0}(\mathrm{~mm})$ & -1.384 & 0.879 & 0.332 \\
\hline 5.928 & $\begin{array}{c}\mathrm{AUPP} \\
(\mathrm{mm})\end{array}$ & -1.144 & 0.815 & 0.411 \\
\hline-0.877 & $\begin{array}{c}\mathrm{ISM}(\mathrm{kN} / \\
\mathrm{mm})\end{array}$ & 0.0509 & 0.916 & 0.277 \\
\hline 6.533 & $D_{3}(\mathrm{~mm})$ & -5.592 & 0.949 & 0.215 \\
\hline 6.073 & $\mathrm{SCI}(\mathrm{mm})$ & -5.246 & 0.769 & 0.459 \\
\hline 5.323 & $\mathrm{BCI}(\mathrm{mm})$ & -6.807 & 0.900 & 0.302 \\
\hline 5.804 & $\mathrm{BDI}(\mathrm{mm})$ & -4.553 & 0.849 & 0.371 \\
\hline
\end{tabular}

usefulness of HWD surface deflections in developing deflection-based airport pavement rutting failure criteria.

\section{Summary and conclusions}

In the past, pavement surface deflections have been successfully used as an indicator of airport pavement life. In this study, the pavement surface deflections measured prior to trafficking were related to rutting performance of four flexible pavement test sections at the FAA's National Airport Pavement Test Facility (NAPTF). A simplified approach for predicting the allowable load repetitions of New Large Aircraft (NLA) loading for airport flexible pavements based on Non-Destructive Test (NDT) data was developed.

Traffic testing were conducted on four flexible test sections, with variable (unbound layer) thicknesses, using a six-wheel aircraft landing gear on one lane and a four-wheel aircraft landing gear on another lane until the test sections were deemed failed. Heavy Weight Deflectometer (HWD) tests were conducted prior to trafficking to measure the pavement surface deflections. Transverse surface profile measurements were made at frequent intervals throughout the traffic testing to monitor the progression of surface rut depths. The following conclusions are drawn from this study:

1. The NAPTF structural failure criterion did not yield consistent rut depths as the criterion is based on the magnitude of surface upheaval and there is no limit on the maximum allowable rut depth.

2. A functional failure criterion was defined based on the number of load repetitions to reach specific rut depth levels: $25.4 \mathrm{~mm}$ (1 in.), $38.1 \mathrm{~mm}$ (1.5 in.), 50.8 $\mathrm{mm}$ (2.0 in.), etc. Performance criteria of this type will limit the total surface rutting and ensure stable rutting performance.

3. The initial HWD surface deflections and the derived Deflection Basin Parameters (DBPs) were related to NAPTF rutting performance in terms of functional failure criteria through regression analysis.

4. These results indicate the usefulness of HWD surface deflections in developing deflection-based airport pavement rutting failure criteria and for predicting the pavement performance of airport flexible pavements serving the next generation of aircrafts.

5. Although, these results are applicable specifically for the six-wheel and four-wheel NLA gears used at NAPTF, the methodology can be easily extended to prototype NLA gear loading with additional data from such full-scale traffic tests.

\section{Acknowledgments}

This paper was prepared from a study conducted in the Center of Excellence (COE) for Airport Technology. Funding for the COE is provided in part by the FAA under Research Grant Number 95-C-001. The COE is maintained at the University of Illinois at Urbana-Champaign who works in partnership with Northwestern University and the FAA. Ms. Patricia Watts is the FAA Program 
Manager for Air Transportation Centers of Excellence and Dr. Satish Agarwal is the Manager of the FAA Airport Technology R \& D Branch. The contents of this paper reflect the views of the authors who are responsible for the facts and accuracy of the data presented within. The contents do not necessarily reflect the official views and policies of the Federal Aviation Administration. This paper does not constitute a standard, specification, or regulation. The assistance rendered by Dr. Gordon Hayhoe and Dr. David Brill of FAA; Dr. Navneet Garg of SRA International, Inc.; and Dr. Franco Gomez-Ramirez of EPSA-LABCO, Santo Domingo, Dominican Republic are gratefully acknowledged.

\section{References}

Ahlvin, R. G.; Ulery, H. H.; Hutchinson, R. L. and Rice, J. L. 1971. Multiple-wheel heavy gear load pavement tests. Vol. 1: Basic Report, Technical Report No. AFWL-TR-70-113, U.S. Army Engineer Waterways Experiment Station, Vicksburg, Mississipi.

Ahlvin, R. G. 1991. Origin of developments for structural design of pavements. Technical Report No. GL-91-26, 1991, U.S. Army Engineer Waterways Experiment Station, Vicksburg, MS.

Bush, A. J. III and Baladi, G. Y. 1989. Nondestructive testing of pavements and backcalculation of moduli, ASTM Special Technical Publication (STP) 1026, ASTM International, West Conshohocken, PA.

Bush, A. L. and Thompson, M. R. 1990. Predicting capacities of low volume airfield pavements, in Proceedings of the Third International Conference on Bearing Capacity of Roads and Airfields, Trondheim, Norway.

Chan, W. K. F.; Rowe, G. M. and Armitage, R. J. 1993. Evaluation and overlay design of airport pavements, in Proceedings of the 1993 ASCE Airfield Pavement Specialty Conference, Vicksburg, MS.

FAA. 2004. Use of nondestructive testing in the evaluation of airport pavements, FAA Advisory Circular No. 150/537011A, Office of Airport Safety and Standards, Federal Aviation Administration.

Garg, N. and Marsey, W. H. 2002. Comparison between falling weight deflectometer and static deflection measurements on flexible pavements at the National Airport Pavement Test Facility (NAPTF), in Proceedings of the 2002 Federal Aviation Administration Airport Technology Transfer Conference, Chicago, IL, 2002.

Gopalakrishnan, K. 2004. Performance analysis of airport flexible pavement subjected to new generation aircraft. Ph.D. Dissertation, University of Illinois, Urbana-Champaign, December.

Gopalakrishnan, K. and Thompson, M. R. 2005. Use of deflection basin parameters to characterize structural degradation of airport flexible pavements, in Proceedings of the ASCE Geo-Institute and Geosynthetics 2005 Congress Conference, Austin, TX.

Gopalakrishnan, K. and Thompson, M. R. 2006. Severity effects of dual-tandem and dual-tridem repeated heavier aircraft gear loading on pavement rutting performance, International Journal of Pavement Engineering 7(3): 179-190.

Gopalakrishnan, K. and Thompson, M. R. 2007. Use of nondestructive test deflection data for predicting airport pavement performance, Journal of Transportation Engineering 133(6): 389-395.
Guo, E. J. and Marsey, W. 2001. Verification of curling in PCC slabs at FAA national airport pavement test facility, in Proceedings of the 2001 ASCE Airfield Pavement Specialty Conference, Chicago, IL.

Hayhoe, G. F. and Garg, N. 2001. Material properties database for the test pavements at the National Airport Pavement Test Facility (NAPTF). Technical Report, Airport Technology Research and Development Branch, Federal Aviation Administration, NJ.

Hayhoe, G. H. 2004. Traffic testing results from the FAA's national airport pavement test facility, in Proceedings of the 2nd International Conference on Accelerated Pavement Testing, University of Minnesota, Minneapolis, MN.

Hill, H. J. and Thompson, M. R. 1989. Early life study of the FA409 full-depth asphalt concrete pavement sections. Unpublished Research Report, 1988, University of Illinois at Urbana-Champaign, Urbana, IL.

Hoffman, M. S. and Thompson, M. R. 1982. Backcalculating nonlinear resilient moduli from deflection data. Transportation Research Record No. 852, TRB, National Research Council: Washington, DC.

Holt, F. B.; Wormald, S. and Tindall, P. 2002. Airport pavement management systems - the next generation, in Proceedings of the 2002 Federal Aviation Administration Airport Technology Transfer Conference, Atlantic City, NJ.

Horak, E. 1987. The use of surface deflection basin measurements in the mechanistic analysis of flexible pavements, in Proceedings of the Sixth International Conference on Asphalt Pavements, University of Michigan, Ann Arbor, MI.

Hossain, S. M. and Zaniewski, J. P. 1991. Characterization of falling weight deflectometer deflection basin. Transportation Research Record No. 1293, TRB, National Research Council: Washington, DC.

Kilareski, W. P. and Anani, B. A. 1982. Evaluation of in-situ moduli and pavement life from deflection basins, in Proceedings of the Fifth International Conference on Asphalt Pavements, University of Michigan, Ann Arbor, MI.

McQueen, R. D.; Marsey, W. and Arze, J. M. 2001. Analysis of nondestructive data on flexible pavement acquired at the national airport pavement test facility, in Proceedings of the 2001 ASCE Airfield Pavement Specialty Conference, Chicago, IL.

Monismith, C. L.; Ogawa, N. and Freeme, C. R. 1975. Permanent deformation characteristics of subgrade soils due to repeated loading. Transportation Research Record No. 537, TRB, National Research Council: Washington, DC.

NCHRP. 1990. Calibrated mechanistic structural analysis procedures for pavements. Final Report, National Cooperative Highway Research Program Project 1-26, TRB, National Research Council, Washington, DC.

Tayabji, S. D. and Lukanen, E. O. 2000. Nondestructive testing of pavements and backcalculation of moduli. ASTM Special Technical Publication (STP) 1375, ASTM International, West Conshohocken, PA.

US COE. 2001. O\&M: PAVER, Asphalt surfaced airfields Pavement Condition Index (PCI). Unified Facilities Criteria (UFC). UFC 3-270-06. U.S. Army Corps of Engineers (Preparing Activity). Naval Facilities Engineering Command, Air Force Civil Engineering Support Agency.

Xu, B.; Ranjithan, S. R. and Kim, Y. R. 2001. Development of relationships between FWD deflections and asphalt pavement layer condition indicators. CD-ROM, in Proceedings of the $81^{\text {st }}$ Annual Meeting of the Transportation Research Board, Washington, DC. 